\title{
An aqueous extract of Maerua edulis (Gilg \& Ben) DeWolf tuber is as effective as a commercial synthetic acaricide in controlling ticks on cattle in vivo
}

Emmanuel T Nyahangare ${ }^{1,2}$, Brighton M. Mvumi ${ }^{3 *}$, Christopher Magona ${ }^{1}$, Jacobus N Eloff ${ }^{2}$

${ }^{1}$ University of Zimbabwe, Department of Animal Science, Faculty of Agriculture, P O Box MP167

Mt Pleasant, Harare, ${ }^{2}$ University of Pretoria, Phytomedicine Programme, Department of Paraclinical

Sciences, Faculty of Veterinary Science, Private Bag X04, Onderstepoort0110, South Africa,

${ }^{3}$ University of Zimbabwe, Department of Soil Science \& Agricultural Engineering, Faculty of Agriculture, P O Box MP167 Mt Pleasant, Harare,

*Corresponding author: mvumibm@ hotmail.com, mvumibm@agric.uz.ac.zW

\begin{abstract}
Farmers in Zimbabwe claim plant that extracts of Cissus quadrangularis, Aloe vera and Maerua edulis are effective at controlling cattle ticks. On-station experiments were conducted at Henderson Research Station to determine the in-vivo efficacy of crude aqueous extracts of Cissus quadrangularis (succulent stems), Aloe vera (succulent leaves) and Maerua edulis (leaves and tuber) at concentrations of $15 \%, 15 \%$ and $10 \% \mathrm{w} / \mathrm{v}$ respectively, against cattle ticks. An amitraz-based acaricide and water were used as positive and negative controls respectively. Thirty Mashona steers were allocated to the six treatments in a completely randomised design experiment where each animal was an experimental unit replicated five times. The animals were each sprayed weekly with $5 \mathrm{~L}$ of the test or control solutions using a knapsack sprayer after which full body tick counts were recorded every other day for seven weeks. The experiments were conducted between January and February when conditions are optimal for tick development. The M. edulis tuber extract was as effective as the amitraz-based commercial acaricide. The other three plants extracts were however, as ineffective as the negative water control. Maerua edulis tuber, soapy water-oil extract is effective against cattle ticks and have potential to be developed into an acaricidal product and thus benefit mostly resourcechallenged smallholder farmers who cannot afford commercial synthetic acaricides. In vivo studies using acaricidal plants are rare.
\end{abstract}

Keywords: In-vivo acaricidal efficacy; Cattle ticks; Aloe vera; Cissus quadrangularis; Maerua edulis; ticks and tick-borne diseases 


\section{Highlights}

- Maerua edulis tuber aqueous extracts were as effective as synthetic acaricide

- Cissus quadrangularis, M. edulis leaves and Aloe vera not effective

- In-vitro results alone are not conclusive in determining acaricidal efficacy

- Maerua edulis tuber extracts can be developed into a commercial product

- There is scope to further investigate efficacy of M. edulis leaves 


\section{Introduction}

For a long time, researchers and farmers have grappled with the negative effects of ticks and tick-borne diseases particularly on the African continent (Estrada-Peña and Salman, 2013) . Ticks are important vectors of various parasites including Ehrlichia (Cowdria) ruminatium, Theileria parva and Babesia bigemina (Bissinger and Roe, 2010; Wanzala et al., 2012; Adenubi et al., 2016; Vudriko et al., 2016). These vectors cause diseases that affect cattle productivity and profitability including Babesiosis (Red water), Theileriosis (January disease), Cowdriosis (Heart water) and Anaplasmosis (Gall sickness) if not controlled effectively. Effects of ticks are not limited to diseases alone but they also suck blood and can cause ear and teat damage in cattle. Additionally, they can cause tick "worry" and are generally associated with weight loss and reduced productivity of the animals (Kaaya and Knapp, 2003; EstradaPeña and Salman, 2013).

Economically, tick control programmes can take up a significant proportion of the national fiscus (Taylor, 2001; Kaaya and Knapp, 2003; Bowman et al., 2004; Rajput et al., 2006; Mapholi et al., 2014). Globally, the cost of controlling ticks is estimated to range between 13.9 - 18.7 billion US dollars (Estrada-Peña and Salman, 2013). There are many examples in Africa where tick and tick-borne disease control programmes have used up millions of US dollars from the fiscus (Moyo and Masika, 2009; Leta et al., 2013; Mapholi et al., 2014). It is estimated that the annual cost in US dollars of importing acaricides in different African countries are: Zimbabwe \$9.3 million (Perry et al., 1990), Zambia \$10 million (Pegram et al., 1988), Kenya \$16 million (Tatchell et al., 1986), Tanzania and Uganda \$26 million (Kagaruki, 1997; OkelloOnen and Nsumbuga-Mutaka, 1997), and Nigeria \$30 million (Dipeolu, 1991). This is not an African problem alone but other countries also suffer the same fate. Brazil's tick control programmes cost approximately 2 billion US dollars in 2000 (Moyo and Masika, 2013). However, current data on the economic impact of ticks and tick-borne diseases are scarce.

Over the years there have been efforts to look for alternative cost-effective tick control remedies like use of ethnoveterinary plants in response to emerging challenges associated with use of the conventional synthetic acaricides (Isman, 1994; Stevenson et al., 2012; Grzywacz et al., 2013; Khan and Damalas, 2015). These practices have been slowly gaining popularity in many parts of the world particularly in the developing countries (Samie et al., 2010). Traditional practices, especially acaricidal plants, are locally available, affordable and mostly environmentally-benign and therefore can offer a viable alternative or complementary remedy 
to conventional synthetic-based tick control programmes (Njoroge and Bussmann, 2006; Isman, 2008; Pirali-Kheirabadi et al., 2009; Fouche et al., 2016).

Ethnoveterinary studies have provided databases of plants with claimed acaricidal properties globally (Adenubi et al., 2016). In a limited number of cases the efficacy has been examined in in vitro studies. In Zimbabwe, several surveys and literature reviews indicate that many plant species have been used with potential acaricidal activities (Marandure, 2016; Maroyi, 2012; Ndhlovu and Masika, 2012; Nyahangare et al., 2015). Despite the wide availability of these plant species, there are no products available on the market largely because the comprehensive documented scientific evidence of their efficacy is lacking. It is therefore critically important to provide scientific evidence of the efficacy and safety of traditionally acclaimed acaricidal plants for the benefit of the livestock industry.

In most cases where efforts have been made to validate the effectiveness of acaricidal plants, research has been limited to in-vitro laboratory bioassays at the expense of in-vivo trials (Adenubi et al., 2016). This is because in-vivo experiments are expensive and logistically challenging to carry out and many institutions do not have facilities to do these experiments (Moyo et al., 2009; Santillán-Velázquez et al., 2013). However, live animal in-vivo data are crucial because they provide evidence of the efficacy of the plant extracts under field conditions on the animal.

The other challenge is the lack of clear guidance on the registration process of these products as the current regulatory framework was designed for registration of synthetic pesticides (Sola et al., 2014). In many countries, it is a legal requirement to have evidence of in-vivo activity of a particular product and this explains why there are not many plant-based acaricidal products on the formal markets.

In the current study, the acaricidal efficacies of Cissus quadrangularis (L) (Vitaceae), Maerua edulis (Gilg \& Ben) DeWolf (Capparaceae) and Aloe vera (Barbadensis Miller) (L.) Burm.f. (Xanthorrhoeaceae) were tested against cattle ticks in-vivo. These plants were selected because they were initially identified by farmers and other stakeholders as acaricidal in a survey conducted in semi-arid cattle producing areas of Zimbabwe. In the survey, the most frequently mentioned plants used against cattle ticks across the surveyed districts in descending order were: C. quadrangularis (30.1\%), Lippia javanica (Burm.f.) Spreng. (Verbenaceae) (19.6\%), Psydrax livida (Hiern) Bridson (Rubiaceae) (14.9\%) and Aloe sp. (14.9\%) (Nyahangare et al., 2015). It was established from farmers that normally, these plants are prepared by crushing and 
soaking in water overnight and spraying the extract on the animals. In vitro preliminary screening of C. quadrangularis, A. vera and M. edulis showed that water extracts of these plants were indeed acaricidal against tick larvae (Chereni, 2014). While M. edulis was not ranked highly in the survey, the few respondents who used it, claimed that it was very effectiveness. Literature search confirmed that in Zambia some preliminary in-vitro screening of potentially acaricidal plants showed that M. edulis water extract was effective against cattle ticks (Kaposhi, 1992). Lippia javanica was not included in the current study because earlier studies confirmed in-vivo acaricidal activity of the aqueous extracts (Madzimure et al., 2011). The objective of the current study was therefore to confirm farmer claims of acaricidal efficacy of the selected plants while also validating laboratory efficacy findings (Chereni, 2014), under farm conditions.

\section{Materials and methods}

\subsection{Study site}

The study was carried out at Henderson Research Station $\left(17^{\circ} 35^{\prime} \mathrm{S}, 30^{\circ} 58^{\prime} \mathrm{E}\right)$ in Mazowe district about $32 \mathrm{~km}$ north east of Harare. The station is in natural farming region II which receives an average annual rainfall of 750 to $1000 \mathrm{~mm}$. Peak tick infestation occurs during the wet summer months between January and March and the trial was conducted in January and February of 2016. The most common tick species found in the area include Rhipicephalus (Boophilus) microplus Canestrini (Acari: Ixodidae), Rhipicephalus evertsi evertsi Neuman (Acari: Ixodidae), Rhipicephalus appendiculatus Neuman (Acari: Ixodidae), Hyalomma spp. and Amblyomma spp. (Madzimure et al., 2011).

\subsection{Plant collection and preparation of treatments}

Cissus quadrangularis stems and M. edulis leaves and tubers were collected from Chiredzi district about $430 \mathrm{~km}$ south-east of Harare, while A. vera succulent leaves were collected at Henderson Research Station located about $30 \mathrm{~km}$ north of Harare. The plants were positively identified by a qualified botanist, Mr Christopher Chapano and voucher specimens deposited at the National Herbarium and Botanic Gardens of Zimbabwe. The voucher specimen records are: C. quadrangularis (Nyahangare E6), M. edulis (Nyahangare E5) and A. vera (Nyahangare 
E37). The leaves and tubers of M. edulis and fleshy stems of C. quadrangularis and A. vera, were separately crushed and mixed with water containing a $1 \% \mathrm{w} / \mathrm{v}$ detergent (green bar soap) for $24 \mathrm{~h}$ to create a $25 \% \mathrm{~g} / 100 \mathrm{ml}$ stock solution. The green bar soap (Sunlight produced by Unilever Pvt Ltd) is widely available in shops in southern Africa and was added to reduce surface tension of water when applied on the animal bodies. The soap was first pulverized and dissolved in $1 \mathrm{~L}$ of the stock solution and then added back to the parent solution. After $24 \mathrm{~h}$, each mixture was filtered through a mutton cloth and sufficient water added to yield $10 \%$ extracts v/v of M. edulis leaves and tubers and $15 \%$ v/v of $C$. quadrangularis and A. vera. Vegetable cooking oil (Olivine brand, Olivine Industries Pvt Ltd, Harare, Zimbabwe) was added to each preparation at $2 \% \mathrm{w} / \mathrm{v}$. The vegetable oil was used as a low-cost measure of maintaining and preserving the acaricidal properties of the plant extracts and to aid in penetrating the tick cuticle. Olive oil is a better product but is not affordable to the intended beneficiaries of these technologies. The concentrations (10\% and $15 \%)$ were optimal recommendations from earlier laboratory bioassays (Chereni, 2014). The plant-based treatments were compared to a positive control of Triatix ${ }^{\circledR}$ spray $(12.5 \%$ EC amitraz-based compound manufactured by Ecomed Manufacturing, Belmont, Zimbabwe for Coopers Zimbabwe Private Ltd), applied at the prescribed (label) dilution rate of $0.2 \% \mathrm{v} / \mathrm{v}$ (Table 1). The negative control consisted of the surfactant, the vegetable oil and water.

\subsection{Experimental animals and design}

Thirty Mashona steers of the same age (approximately two years) and raised under the same environmental conditions at Henderson Research Station were used. The steers were randomly allocated to the six treatments with each steer acting as an experimental unit and replicated 5 times in a complete randomized design experiment. Treatments were applied weekly in accordance with the Government of Zimbabwe regulations for summer dipping as opposed to fortnightly for winter dipping (Ndhlovu et al., 2009; Masuku et al., 2015). 


\section{Table 1 Summary of experimental treatments}

\begin{tabular}{ll}
\hline Treatment & \multicolumn{1}{c}{ Description } \\
\hline $\mathbf{1}$ & $10 \% \mathrm{w} / \mathrm{v}$ Maerua edulis leaves water extract $+1 \% \mathrm{w} / \mathrm{v}$ surfactant $+2 \% \mathrm{w} / \mathrm{v}$ \\
& vegetable cooking oil \\
$\mathbf{2}$ & $10 \% \mathrm{w} / \mathrm{v}$ Maerua edulis tubers water extract $+1 \% \mathrm{w} / \mathrm{v}$ surfactant $+2 \% \mathrm{w} / \mathrm{v}$ \\
& vegetable cooking oil \\
$\mathbf{3}$ & $15 \% \mathrm{w} / \mathrm{v}$ Aloe vera water extract $+1 \% \mathrm{w} / \mathrm{v}$ surfactant $+2 \% \mathrm{w} / \mathrm{v}$ vegetable \\
& cooking oil \\
$\mathbf{4}$ & $15 \% \mathrm{w} / \mathrm{v}$ Cissus quadrangularis water extract $+1 \% \mathrm{w} / \mathrm{v}$ surfactant $+2 \% \mathrm{w} / \mathrm{v}$ \\
& vegetable cooking oil \\
$\mathbf{5}$ & Water with 1\% w/v surfactant and 2\% w/v vegetable cooking oil $(\mathrm{Negative}$ \\
& control)
\end{tabular}

The surfactant was a commercial washing solid soap pulverized and dissolved in 1 L of the stock solution and then added back to the parent solution. The vegetable oil was a commercial brand. 


\subsection{Experimental procedure}

Prior to commencement of the experiment, the cattle were exposed to natural tick infestation for 14 days (adaptation period) after which they were subjected to the treatments. During treatments, each animal was restrained in a cattle-crush and a full body tick count for different species made and recorded. After counting, each animal was sprayed with $5 \mathrm{~L}$ test extract using a knapsack sprayer. The ticks on the animals were counted every other day thereafter for seven weeks from February to March (duration of the trial). The treatments were applied weekly after counting the ticks. Animals in different treatments were kept in separate paddocks throughout the experiment to avoid cross contamination. All animals were closely monitored throughout the experiment for any signs of tick-borne and other diseases by a veterinary practitioner at Mazowe Veterinary College, located approximately 1 km north of Henderson Research Station, Zimbabwe.

\subsection{Data analysis}

The efficacy ratio per animal was calculated from the daily tick counts using the formula adapted from O’Neill (2006).

$$
\text { Acaricidal efficacy }=1-\left(\frac{\text { Treatment tick count }}{\text { Untreated control tick count }}\right)
$$

The repeated measures analysis of variance the mean efficacy ratios was conducted using the GLM procedures of SAS version 9. 3.1 (SAS, 2006) using the following statistical model:

Yijk $=\mu+T i+W j+T i \times W j+e i j k$

Where:

$>$ Yijk is the response variable (tick count efficacy ratio)

$>\mu$ is the overall population mean

$>\mathrm{Ti}$ is the fixed effect of the $\mathrm{i}^{\text {th }}$ treatment $(\mathrm{i}=$ treatment $(1, \ldots .5)$

$>\mathrm{Wj}$ is the fixed effect of time post-treatment application $(\mathrm{j}=$ weeks $1, \ldots 7$ )

$>\mathrm{Ti} \times \mathrm{Wj}$ is the interaction between time post-treatment application and treatment

$>$ eijk is the residual error 


\section{Results}

\subsection{Acaricidal efficacy ratios}

Maerua edulis tuber aqueous extract was the only plant-based treatment with high efficacy ratios against cattle ticks with a mean overall efficacy ratio of $80 \%$ over the seven weeks of study (Figure 1). There was no statistically significant difference $(p>0.05)$ in efficacy between the tuber extract and the positive control $\left(\right.$ Triatix $\left.^{\circledR}\right)$ throughout the experimental period. In the seven weeks, the tuber extracts had efficacy ratios of greater than $50 \%$ (Fig. 1). Maerua edulis leaves, $A$. vera and $C$. quadrangularis treatments were not effective in reducing tick loads and were not significantly different from the negative control (water) $(p>0.05)$.

The weekly overall mean efficacy ratios of treatments between sprayings and after spraying are presented in Table 2. M. edulis tuber was the only plant based treatment that was significantly effective against cattle ticks.

\subsection{The variation of total tick populations over time}

There was both a time and time*treatment effect on total tick population $(\mathrm{p}<0.05)$. In the first week there was a general increase in the number of ticks for both treatments although the degree of increase differed among treatments. The least increase was on Triatix ${ }^{\circledR}$ (positive control), and the M. edulis tuber treatments (Fig 2), while in the other plant-based treatments $(C$. quadrangularis, A vera and $M$. edulis leaf) there was a higher record of ticks on the animals. The negative control of water had the highest record of ticks. However, over time, the total tick population across the treatments was reduced significantly. 


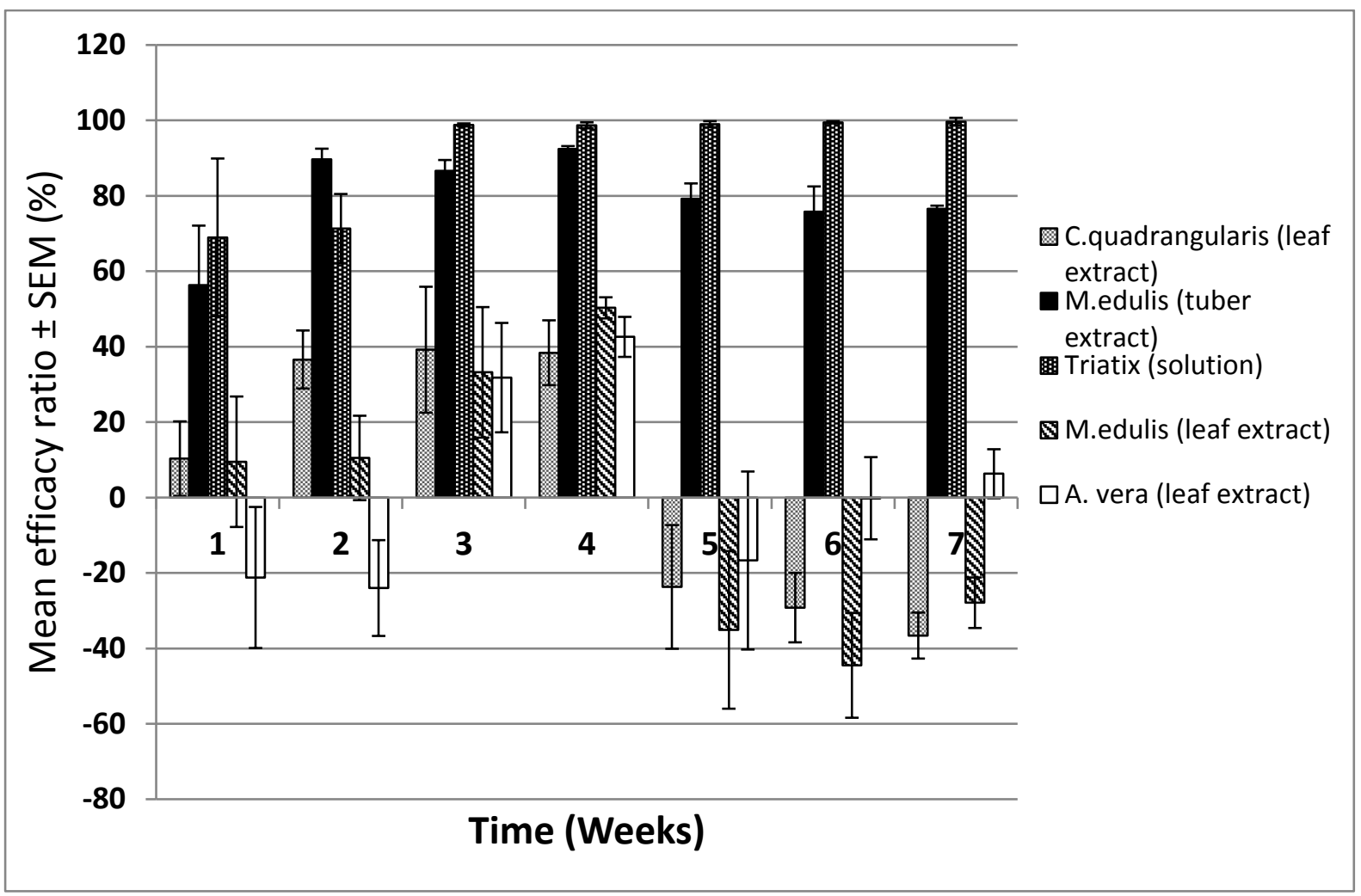

Figure 1: Mean weekly efficacy ratios of treatments against cattle ticks over 7 weeks compared to negative control water (February-March 2016) $(n=5)$ 
Table 2: Least square mean tick mortality ratios (\%) for treatments against counting time within weeks $(n=7)$

\begin{tabular}{lllll}
\hline Treatment & Count 0 & Count 1 & Count 2 & Count 3 \\
\hline M. edulis (leaf) & $-14.0^{\mathrm{a}}$ & $-25.5^{\mathrm{a}}$ & $-39.0^{\mathrm{a}}$ & $-15.5^{\mathrm{a}}$ \\
M. edulis (tuber) & $71.5^{\mathrm{b}}$ & $76.7^{\mathrm{b}}$ & $71.5^{\mathrm{b}}$ & $69.4^{\mathrm{b}}$ \\
Triatix $^{\circledR}$ & $82.5^{\mathrm{b}}$ & $94.7^{\mathrm{b}}$ & $89.1^{\mathrm{b}}$ & $91.2^{\mathrm{b}}$ \\
A. vera & $-40.4^{\mathrm{a}}$ & $-6.4^{\mathrm{a}}$ & $-36.1^{\mathrm{a}}$ & $-13.4^{\mathrm{a}}$ \\
C. quadrangularis & $-43.9^{\mathrm{a}}$ & $-27.1^{\mathrm{a}}$ & $-39.5^{\mathrm{a}}$ & $-30.1^{\mathrm{a}}$ \\
\pm SEM & 17.7 & $11.4^{\mathrm{a}}$ & 14.9 & 11.6
\end{tabular}

Within the column means with different superscripts are significantly different $(p<0.05)$.

$S E M=$ standard error of mean 


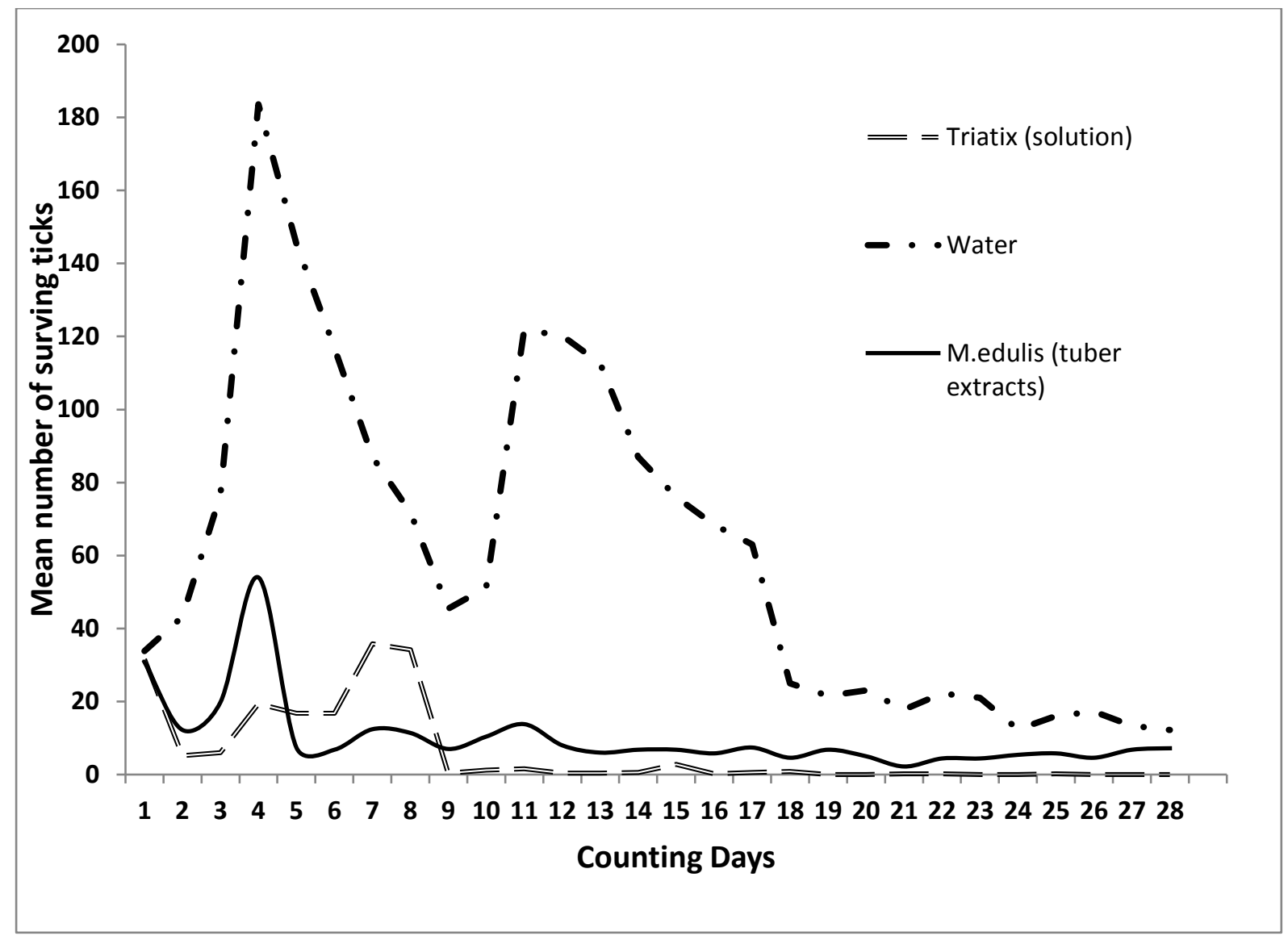

Figure 2: Mean overall ticks surviving in the Maerua edulis tuber extract compared to negative and positive treatments over 7 weeks from February to March $2016(n=5)$ 


\subsection{Engorged and tick species identified}

In the $M$. edulis leaves, $C$. quadrangularis, $A$. vera extracts and water treatments, there was a high number of engorged ticks. Only a few engorged ticks were found in the M. edulis tuber treatment and the positive control Triatix ${ }^{\circledR}$ (Fig 3). The largest population of ticks for all treatments was of brown ear tick, $R$. appendiculatus followed by blue ticks, Boophilus decoloratus (Koch) (Acari: Ixodidae). There were no Bont tick (Ambylomma spp.) recorded throughout the experiments and very few Red-legged, $R$. evertsi as well as Bont legged (Hyalomma spp.) were recorded including a species which was classified under other ticks. There was a slight increase in the numbers of Red-legged ticks in contrast to Brown ear ticks towards the end of the experiments although the numbers were still lower than for Brown ear ticks.

\section{Discussion}

The $M$. edulis tuber treatments showed high efficacy comparable to the synthetic acaricide $\left(\right.$ Triatix $\left.^{\circledR}\right)$. Similar results were reported of the same extract but against tick larvae in the laboratory (Simuunza et al., 2011). The mean tick count for the tuber extract treatment was 9.8 ticks per animal which implies that the animals were not tick infested according to Zimbabwe Veterinary standards which stipulate that when more than $10 \%$ of the animals have 10 or more live ticks, they are considered tick infested (Madzimure et al., 2011)

The acaricidal efficacy observed in the $M$. edulis tuber extracts could have been caused by the presence of linear chain unsaturated fatty acids which were found to be the main active ingredients upon preliminary phytochemical analysis (Luo et al., 2011). In the current study, water extract of $M$. edulis leaves was not effective in reducing tick numbers which contradicts 


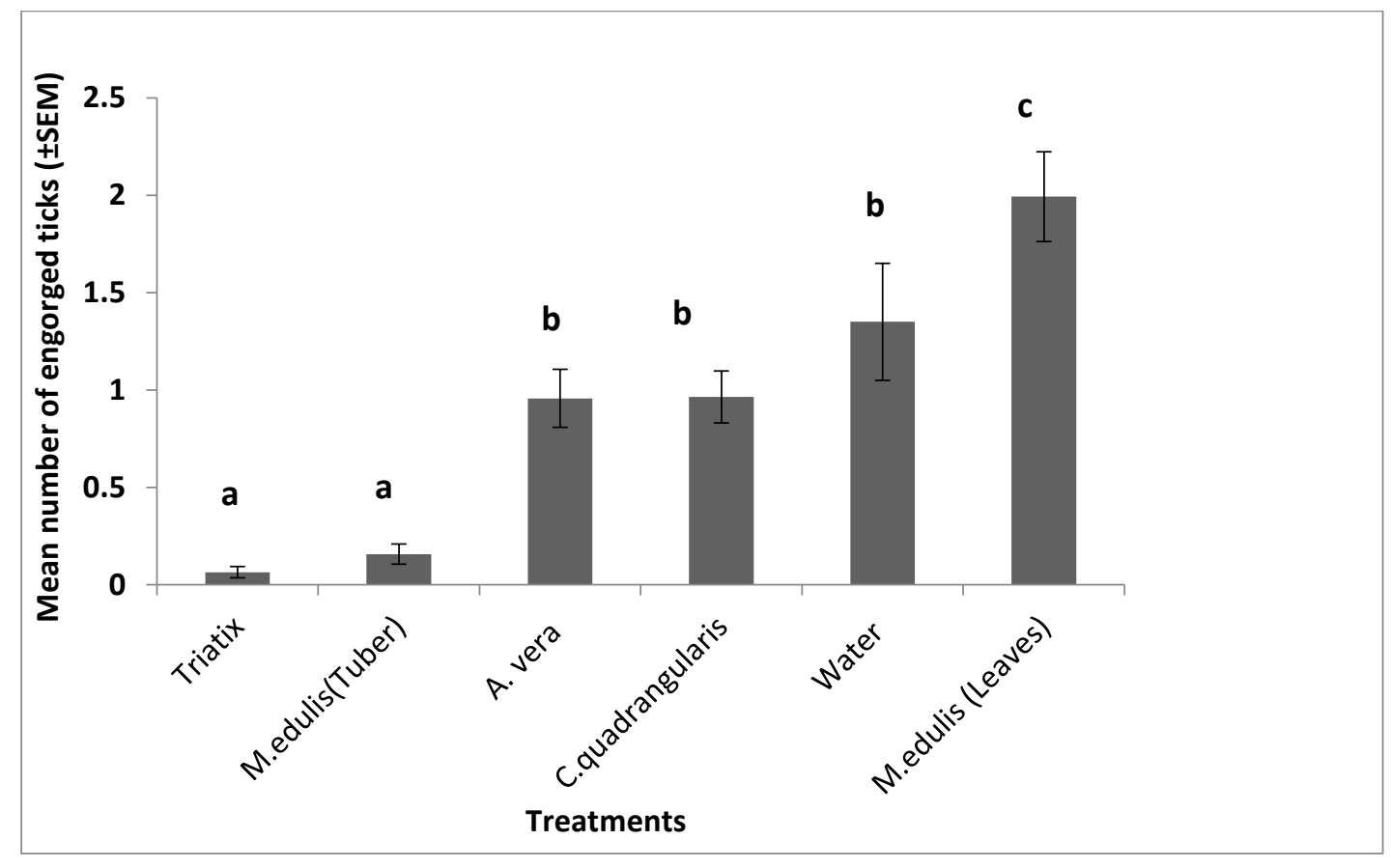

Figure 3: Average number of engorged ticks in the different treatments over 7 weeks $(n=5)$. Treatment means with different letters $(a, b \& c)$ are significantly different 
preliminary in-vitro bioassays results on tick larvae (Chereni, 2014) and strong perceptions expressed by farmers on the effectiveness of the leaf extracts against pests (Stathers et al., 2002; Nyahangare et al., 2015). However, literature on the chemistry of this plant is scant despite its potential in animal and human health. Some members of the Capparaceae family, including Marua angolensis DC. were found to have anthelmintic characteristics against the parasitic nematode Haemonchus contortus (Rudolphi) Cobb (Strongylida: Trichostrongylidae) and the activity was ascribed to presence of kaempferol-based and quercetin-based flavonols (Mengistu et al., 2017).

Studies have shown that water is a very poor extractant for antimicrobial and antiparasitic compounds from plants compared to acetone and other intermediate polarity solvents (Eloff, 1988; Kotze and Eloff, 2002; Zorloni et al., 2010). In the current experiments we focused on using an extractant that could be easily available to rural farmers and could deliver active extracts. To increase the solubility of relatively non-polar compounds, soap and oil was added to the water. Perhaps using organic solvents can increase the efficacy of the M. edulis leaves because it is known that water has limited extraction properties. Solvents like acetone, which extract a wide array of active compounds and are less toxic to the ticks, may possibly lead to better results (Eloff, 1998; Zorloni et al., 2010). However, acetone cannot possibly be used to treat animals for tick control.

The increase in efficacy in the tuber extracts from week 1 to week 5 could be due to residual effects. It is an indication that apart from the dose-dependency characteristics evident with most conventional acaricides, residual effects may also influence efficacy with increase in application over time. Such a phenomenon is very desirable in the use of acaricidal plants and has been previously reported in another acaricidal plant, L. javanica. At the $5 \% \mathrm{w} / \mathrm{v}$ concentration, there was a significant increase in efficacy over time with subsequent applications (Madzimure et al., 2011).

Aloe vera, M. edulis (leaf) and C. quadrangularis water extracts had no significant acaricidal activity against cattle ticks. This is despite the fact that these plants had been ranked very highly by rural farmers in Zimbabwe in a survey by Nyahangare et al. (2015). In Chiredzi district of Zimbabwe, respondents call C. quadrangularis "Chiololo" in their language of Kalanga which loosely translates to "deadly effective" in English. The variance in activity may possibly be explained after a phytochemical analysis to identify the different active components in the water extracts. It has been reported before that $C$. quadrangularis contains a number of 
bioactive compounds which include alkaloids, resveratrol, piceatannol, pallidol, parthenocissin, quadrangularins, ascorbic acid, carotene, phytosterol substances, calcium, flavonoids, vitamins, enzymes, nicotinic acid, tyrosin and triterpenoids (Joseph and Raj, 2011; Mishra et al., 2010; Rao and Annamalai, 2011). Because of this rich mix of compounds this plant has been reported to have antioxidant (Jainu and Devi, 2005), antibacterial (Murthy et al., 2003), antiosteporosis (Shirwaikar et al., 2003), anti-tumour (Opoku et al., 2000) among other medicinal properties. If reports of acaricidal properties could be confirmed, this will make this plant very special. One of the few reports on activity of water extracts of $C$. quadrangularis against ticks shows that silver nanoparticles made from its stem showed positive results against R. (B.) microplus tick larvae and Hippobosca maculata L. (Diptera, Hippoboscidae) compared to water extracts (Santhoshkumar et al., 2012). The activity may be caused by the silver nanoparticles and not by a compound from the plant. On the other hand, A. vera was shown to be moderately acaricidal against ticks, fleas and mosquitos in in vitro experiments in addition to its anti-coccidiosis activity (Urch, 1999; Chereni, 2014). The negative results obtained with M. edulis leaves, $A$. vera and $C$. quadrangularis extracts in this study are contrary to the results from laboratory trials by Chereni (2014). This questions the validity of laboratory results without confirming the activity in animal studies. According to Lim (2011), factors such as temperature, sunlight, as well as air properties could contribute to plant loss of pesticidal efficacy. If the compounds responsible for activity in in vitro studies with $A$. vera and $C$. quadrangularis extracts are thermolabile or susceptible to photooxidation and the compounds in M. edulis tuber extracts are not sensitive, it could explain the results obtained. Therefore, further research need to be conducted to establish the exact cause for loss of acaricidal properties when the same extracts are tested in-vivo.

It is disappointing that the $M$. edulis leaf water extract had no activity against the ticks because the sustainable use of $M$. edulis tuber extracts to protect animals against ticks is questionable. Water is a poor solvent compared to other extractants, especially acetone, in determining antimicrobial and antiparasitic activities (Eloff, 1988; Kotzé et al., 2002). Therefore, there is potential to optimise the extraction from both $M$. edulis leaves and tubers using organic solvents.

The general decline in total tick count over time is not unexpected because tick populations naturally decline as the summer season progresses and rainfall and temperatures decrease because ticks prefer warm and wet conditions (Muchenje et al., 2008). This is why in Zimbabwe dipping is done on a weekly basis in summer and fortnightly in winter in the normal 
tick management systems. This balance may be changing because of the changing climatic and weather patterns (Collier et al., 2008; Estrada-Peña and Salman, 2013).

There was no change in tick species that are commonly found at the research station with $B$. decoloratus (blue tick), R. appendiculatus (brown ear tick), Hyalomma species and R. evertsi evertsi (red legged tick) found during the trial. All previous trials at the station recorded the same tick species (Madzimure et al., 2011; 2013).

The high number of engorged ticks which were present on A. vera, M. edulis leaves and $C$. quadrangularis treatments and the negative control, is an indication that ticks were not adversely affected and thus would drop off naturally after being fully engorged so that they would lay eggs (Madzimure et al., 2011). On the contrary, in the positive control and the $M$. edulis tuber treatment, there were fewer engorged ticks recorded on the cattle showing a possible negative effect on the reproductive activities of the ticks.

\section{Conclusion}

This study showed that $M$. edulis tuber water extracts containing a surfactant and vegetable oil can effectively reduce tick populations on cattle and can be used as an alternative to synthetic acaricides in controlling cattle ticks. Cissus quadrangularis, A. vera and M. edulis leaf water extracts were not significantly effective against cattle ticks compared to the negative control.

Further investigations are required to compare the in vivo efficacy of different concentrations of the tuber extracts. Identification of the anti-tick compounds in the tuber extract could provide useful information and may lead to the identification of a new acaricidal compound. Issues such as optimisation of the extraction, health and safety, propagation and sustainable harvesting should also be investigated. It may be very interesting to investigate why our results differed from the traditional use and from laboratory results. There is also need to determine the possible effects of the harvesting timing on the chemical composition and acaricidal activity of both the M. edulis leaves and tuber. It could be one of the reasons causing the differential acaricidal activity that was observed. 


\section{Acknowledgements}

The authors acknowledge financial support received from the European Commission's European Development Fund ACP S\&T Programme grant FED /2013/329272 (OPTIONs). The authors are grateful to Henderson Research Institute, Zimbabwe for supplying the cattle, facilities and technical support. Staff at Mazowe Veterinary College, Zimbabwe are acknowledged for providing technical expertise in screening cattle blood samples for parasites. The expertise provided in the correct identification of plant species from the staff at the Zimbabwe National Herbarium and Botanic Garden is greatly appreciated.

\section{References}

Adenubi, O.T., Fasina, F.O., McGaw, L.J., Eloff, J.N., Naidoo, V., 2016. Plant extracts to control ticks of veterinary and medical importance: A review. South African J. Bot. 105, 178-193. doi:10.1016/j.sajb.2016.03.010

Bissinger, B.W., Roe, R.M., 2010. Tick repellents: Past, present, and future. Pestic. Biochem. Physiol. 96, 63-79. doi:10.1016/j.pestbp.2009.09.010

Bowman, A.S., Nuttall, P.A., Chappell, L.H., 2004. Ticks: biology, disease and control. Parasitology 129 Suppl, S1. doi:10.1017/S0031182004006560

Chereni, P. 2014. Acaricidal activity of crude water extracts of selected indigenous plants against Rhipicephalus appendiculatus ticks. BSc Honours dissertation. Department of Animal Science. University of Zimbabwe.

Collier, P., Conway, G., Venables, T., 2008. Climate change and Africa. Oxford Rev. Econ. Policy 24, 337-353. doi:10.1093/oxrep/grn019

Dipeolu, O.O., and Ndungu, J.N., 1991. Acaricidal activity of "Kupetaba", a ground mixture of natural products against Rhipicephalus appendiculatus. Vet. Parasitol. 38, 327-338.

Eloff, J.N., 1998. Which extractant should be used for the screening and isolation of antimicrobial components from plants? J. Ethnopharmacol. 60, 1-8. doi:10.1016/S03788741(97)00123-2

Estrada-Peña, A., Salman, M., 2013. Current limitations in the control and spread of ticks that affect livestock: A review. Agriculture 3, 221-235. doi:10.3390/agriculture3020221

Fouche, G., Ramafuthula, M., Maselela, V., Mokoena, M., Senabe, M., Leboho, T., Sakong, B.M., Adenubi, O.T., Eloff, J.N. Wellington, K.W., 2016. Acaricidal activity of the 
organic extracts of thirteen South African plants against Rhipicephalus (Boophilus) decoloratus (Acari: Ixodidae). Vet. Parasitol. 224, 39-43

Grzywacz, D., Stevenson, P.C., Mushobozi, W.L., Belmain, S., Wilson, K., 2013. The use of indigenous ecological resources for pest control in Africa. Food Secur. 1-16. doi:10.1007/s12571-013-0313-5

Isman, M.B., 1994. Botanical insecticides. Pestic. Outlook.

Isman, M.B., 2008. Botanical insecticides : for richer, for poorer. Pest Manag. Sci. 11, 8-11. doi:10.1002/ps

Kaaya, G.P., Knapp, M., 2003. Prospects for innovative tick control methods in Africa. Insect Sci. Appl. 23, 59-67.

Kagaruki L. 1997. Country Report, Tanzania, pp. 10-In Proceedings of International Tick Modelling Workshop, 9-19 September 1997. ICIPE Science Press, Nairobi, Kenya.

Khan, M., Damalas, C.A., 2015. Factors preventing the adoption of alternatives to chemical pest control among \{Pakistani\} cotton farmers. Int. J. Pest Manag. 61, 9-16. doi:10.1080/09670874.2014.984257

Kotze, M., Eloff, J.N., 2002. Extraction of antibacterial compounds from Combretum microphyllum (Combretaceae). South African J. Bot. 68, 62-67. doi:10.1016/S02546299(15)30442-7

Leta, S., De Clercq, E.M., Madder, M., 2013. High-resolution predictive mapping for Rhipicephalus appendiculatus (Acari: Ixodidae) in the Horn of Africa. Exp. Appl. Acarol. 60, 531-542. doi:10.1007/s10493-013-9670-1

Lim, E., Sik Roh, H., Coudron, T.A., Park, C.G., 2011. Temperature-Dependent Fumigant Activity of Essential Oils Against Twospotted Spider Mite (Acari: Tetranychidae). Journal of Economic Entomol. 104, (2) 414-419 doi: 10.1603/EC10249

Luo, X., Pires, D., Aínsa, J.A., Gracia, B., Mulhovo, S., Duarte, A., Anes, E., Ferreira, M.J.U., 2011. Antimycobacterial evaluation and preliminary phytochemical investigation of selected medicinal plants traditionally used in Mozambique. J. Ethnopharmacol. 137, 114-120. doi:10.1016/j.jep.2011.04.062

Madzimure, J., Nyahangare, E.T., Hamudikuwanda, H., Hove, T., Belmain, S.R., Stevenson, P.C., Mvumi, B.M., 2013. Efficacy of Strychnos spinosa (Lam.) and Solanum incanum L. aqueous fruit extracts against cattle ticks. Trop. Anim. Health Prod. 45, 1341-1347. doi:10.1007/s11250-013-0367-6

Madzimure, J., Nyahangare, E.T., Hamudikuwanda, H., Hove, T., Stevenson, P.C., Belmain, S.R., Mvumi, B.M., 2011. Acaricidal efficacy against cattle ticks and acute oral toxicity 
of Lippia javanica (Burm F.) Spreng. Trop. Anim. Health Prod. 43, 481-489. doi:10.1007/s11250-010-9720-1

Mapholi, N.O., Marufu, M.C., Maiwashe, A., Banga, C.B., Muchenje, V., MacNeil, M.D., Chimonyo, M., Dzama, K., 2014. Towards a genomics approach to tick (Acari: Ixodidae) control in cattle: A review. Ticks Tick. Borne. Dis. 5, 475-483. doi:10.1016/j.ttbdis.2014.04.006

Marandure, T., 2016. Concepts and key issues of ethnoveterinary medicine in Africa: A review of its application in Zimbabwe. African J. Agric. Res. 11, 1836-1841. doi:10.5897/AJAR2014.8827

Maroyi, A., 2012. Use of traditional veterinary medicine in Nhema communal area of the Midlands Province, Zimbabwe. African J. Tradit. Complement. Altern. Med. 9, 315322. doi:10.4314/ajtcam.v9i3.3

Masuku, J., Dube, A.B., Moyo, B., 2015. The Impact of diptank rehabilitation on the occurrence of Ticks and tickborne diseases in Umzingwane District, Matabeleland. IOSR J. Agric. Vet. Sci. 8, 112-118. doi:10.9790/2380-0822112118

Mengistu, G., Hoste, H., Karonen, M., Salminen, J.-P., Hendriks, W.H., Pellikaan, W.F., 2017. The in vitro anthelmintic properties of browse plant species against Haemonchus contortus is determined by the polyphenol content and composition. Vet. Parasitol. 237, 110-116

Moyo, B., Masika, P.J., 2009. Tick control methods used by resource-limited farmers and the effect of ticks on cattle in rural areas of the Eastern Cape Province, South Africa. Trop. Anim. Health Prod. 41, 517-23. doi:10.1007/s11250-008-9216-4

Moyo, B., Masika, P.J., 2013. Validation of the acaricidal properties of materials used in ethno-veterinary control of cattle ticks 7, 4701-4706. doi:10.5897/AJMR10.308

Moyo, B., Masika, P.J., Dube, S., Maphosa, V., 2009. An in-vivo study of the efficacy and safety of ethno-veterinary remedies used to control cattle ticks by rural farmers in the Eastern Cape Province of South Africa. Trop. Anim. Health Prod. 41, 1569-1576. doi:10.1007/s11250-009-9348-1

Muchenje, V., Dzama, K., Chimonyo, M., Raats, J.G., Strydom, P.E., 2008. Tick susceptibility and its effects on growth performance and carcass characteristics of Nguni , Bonsmara and Angus steers raised on natural pasture. Animal 2, 298-304. doi:10.1017/S1751731107001036

Ndhlovu, D.N., Makaya, P. V, Penzhorn, B.L., 2009. Tick infestation, and udder and teat damage in selected cattle herds of Matabeleland South, Zimbabwe. Onderstepoort J. 
Vet. Res. 76, 235-248.

Ndhlovu, D.N., Masika, P.J., 2012. Ethno-veterinary control of bovine dermatophilosis and ticks in Zhombe, Njelele and Shamrock resettlement in Zimbabwe. Trop. Anim. Health Prod. 45, 525-532. doi:10.1007/s11250-012-0253-7

Njoroge, G.N., Bussmann, R.W., 2006. Herbal usage and informant consensus in ethnoveterinary management of cattle diseases among the Kikuyus (Central Kenya). J. Ethnopharmacol. 108, 332-339. doi:10.1016/j.jep.2006.05.031

Nyahangare, E.T., Mvumi, B.M., Mutibvu, T., 2015. Ethnoveterinary plants and practices used for ecto-parasite control in semi-arid smallholder farming areas of Zimbabwe. J. Ethnobiol. Ethnomed. 11, 30. doi:10.1186/s13002-015-0006-6

Okello-Onen J. and Nsumbuga-Mutaka R. C. 1997. The status of ticks and tick-borne diseases in Uganda, pp. 8-9. In Proceedings of International Tick Modelling Workshop, 9-19 September 1997. ICIPE Science Press, Nairobi, Kenya.

Pegram R. G., Chizyuka H. G. B., Mwase E. T. and Zekle Z. 1988. Production economics in worldwide animal commodities subject to disease transmission and infestation by acarines: The economic impact of cattle tick control in Central Africa. Nat. Symp.Theileriosis, 17-19 October, Lusaka, Zambia

Perry B. D., Mukhebi A. W., Norval R. A. I. and Barret J. C. 1990. A preliminary assessment of current and alternative tick-borne disease control strategies in Zimbabwe. Report to the Director of Veterinary Services, Zimbabwe. 41 pp

Pirali-Kheirabadi, K., Razzaghi-Abyaneh, M., Halajian, A., 2009. Acaricidal effect of Pelargonium roseum and Eucalyptus globulus essential oils against adult stage of Rhipicephalus (Boophilus) annulatus in- vitro. Vet. Parasitol. 162, 346-349. doi:10.1016/j.vetpar.2009.03.015

Rajput, Z.I., Hu, S., Chen, W., Arijo, A.G., Xiao, C., 2006. Importance of ticks and their chemical and immunological control in livestock. J. Zhejiang Univ. Sci. B 7, 912-21. doi:10.1631/jzus.2006.B0912

Statistical Analysis System (SAS), 2006. Statistical Analysis System User's Guide, (SAS Institute Inc, Raleigh, North Carolina)

Samie, A., Tambani, T., Harshfield, E., Green, E., Ramalivhana, J.N., Bessong, P.O., 2010. Antifungal activities of selected Venda medicinal plants against Candida albicans, Candida krusei and Cryptococcus neoformans isolated from South African AIDS patients. J. Biotechnol. 9, 2965-2976. doi:10.5897/AJB09.1521

Santhoshkumar, T., Rahuman, A.A., Bagavan, A., Marimuthu, S., Jayaseelan, C., Kirthi, 
A.V., Kamaraj, C., Rajakumar, G., Zahir, A.A., Elango, G., Velayutham, K., Iyappan, M., Siva, C., Karthik, L., Rao, K.V.B., 2012. Evaluation of stem aqueous extract and synthesized silver nanoparticles using Cissus quadrangularis against Hippobosca maculata and Rhipicephalus (Boophilus) microplus. Exp. Parasitol. 132, 156-165. doi:10.1016/j.exppara.2012.06.009

Santillán-Velázquez, G., Ibarra-velarde, F., Pérez, B.F., 2013. In Vitro and in Vivo Efficacy of an Experimental Compound against Rhipicephalus (Boophilus) microplus. Ticks. Pharmacol. Pharm. 4, 41-45. doi:10.4236/pp.2013.41005

Simuunza, M., Weir, W., Courcier, E., Tait, A., Shiels, B., 2011. Epidemiological analysis of tick-borne diseases in Zambia. Vet. Parasitol. 175, 331-342. doi:10.1016/j.vetpar.2010.09.027

Sola, P., Mvumi, B.M., Ogendo, J.O., Mponda, O., Kamanula, J.F., Nyirenda, S.P., Belmain, S.R., Stevenson, P.C., 2014. Botanical pesticide production, trade and regulatory mechanisms in sub-Saharan Africa: Making a case for plant-based pesticidal products. Food Secur. 6, 369-384. doi:10.1007/s12571-014-0343-7

Stathers, T.., Chigariro, J., Mudiwa, M., Mvumi, B.., Golob, P., 2002. Small-scale farmer perceptions of diatomaceous earth products as potential stored grain protectants in Zimbabwe. Crop Prot. 21, 1049-1060. doi:10.1016/S0261-2194(02)00089-3

Stevenson, P.C., Nyirenda, S.P., Mvumi, B.M., Sola, P., Kamanula, J.F., Sileshi, G.W., Belmain, S.R., 2012. Pesticidal Plants: A viable alternative insect pest management approach for resource poor farming in Africa. Biopesticdes Environ. Food Secur. Issues Strateg.

Tatchell R. J., Chimwani D., Chirchir J. J., Ongare J. O., Mwangi E., Rinkanya F. and Whittington D. 1986. A study of the justification for intensive tick control in Kenya rangelands. Vet. Record 119,401-403

Taylor, M.A., 2001. Recent developments in ectoparasiticides. Vet. J. 161, 253-268. doi:10.1053/tvj1.2000.0549

Urch, D., 1999. Aloe vera nature's gift. Great Britain: Blackdown Publications, 15. Vudriko, P., Okwee-Acai, J., Tayebwa, D.S., Byaruhanga, J., Kakooza, S., Wampande, E., Omara, R., Muhindo, J.B., Tweyongyere, R., Owiny, D.O., Hatta, T., Tsuji, N., Umemiya-Shirafuji, R., Xuan, X., Kanameda, M., Fujisaki, K., Suzuki, H., 2016. Emergence of multi-acaricide resistant Rhipicephalus ticks and its implication on chemical tick control in Uganda. Parasit. Vectors 9. doi:10.1186/s13071-015-1278-3

Wanzala, W., Takken, W., Mukabana, W.R., Pala, A.O., Hassanali, A., 2012. 
Ethnoknowledge of Bukusu community on livestock tick prevention and control in Bungoma district, western Kenya. J. Ethnopharmacol. 140, 298-324. doi:10.1016/j.jep.2012.01.021.

Zorloni, A., Penzhorn, B.L., Eloff, J.N., 2010. Extracts of Calpurnia aurea leaves from southern Ethiopia attract and immobilise ticks. Vet. Parasitol. 168, 160-164 